\title{
Safety Aspects of Iron in Food
}

\author{
Klaus Schümann \\ Walther-Straub-Institut für Pharmakologie und Toxikologie, Ludwig-Maximilians-Universität München, Deutschland
}

\section{Key Words}

Iron · Upper level · Toxicity · Cardiovascular risk · Cancer

\begin{abstract}
During the last decades efforts regarding dietary iron supply focused mostly on the prevention of deficiencies, especially during growth and pregnancy. Correspondingly, homeostatic mechanisms increase intestinal iron absorption in iron deficiency, but its downregulation at high intake levels seems insufficient to prevent accumulation of high iron stores at high intake. There is no regulated iron excretion in overload. Excess of pharmaceutical iron may cause toxicity and therapeutic doses may cause gastrointestinal side effects. Chronic iron excess, e.g. in primary and secondary hemochromatosis, may lead to hepatic fibrosis, diabetes mellitus and cardiac failure. Chronic intake of $50-100 \mathrm{mg} \mathrm{Fe/day} \mathrm{of} \mathrm{highly}$ bioavailable iron with home-brewed beer in sub-Saharan Africans lead to cirrhosis and diabetes. Applying a safety factor of 2 would lead to an upper safe level of 25-50 mg Fe/day for this endpoint of conventional iron toxicity. However, beyond this kind of damage iron is known to catalyze the generation of hydroxyl radicals from superoxide anions and to increase oxidative stress which, in turn, increases free iron concentration. This self-amplifying process may cause damage to lipid membranes and proteins, which relates radical generation and organ damage after ischemia-reperfusion
\end{abstract}

events to available free iron in clinical and experimental settings. Correspondingly, epidemiological studies as well as observations in heterozygotes for hereditary hemochromatosis suggest that the risk of atherosclerosis and acute myocardial infarction is related to body iron stores, though there is conflicting epidemiological evidence as well. The most recent and best controlled studies, however, support the hypothesis that iron stores are related to cardiovascular risk. Iron-amplified oxidative stress may also increase DNA damage, oxidative activation of precancerogens and support tumor cell growth. This is supported by experimental, clinical and epidemiological observations. Due to these mechanisms high iron stores may present a health hazard. Though this has not been finally proven, available evidence strongly recommends not to increase iron intake beyond physiological requirements. To avoid iron deficiency symptoms, on the other hand, care must be taken to meet recommended daily intake.

Copyright @ 2001 S. Karger AG, Basel

\section{Introduction}

The efforts of the evolution to avoid the hazards of micronutrient deficiency and excess are shared by corresponding regulatory efforts. The 'recommended dietary allowance' (RDA) is supposed to meet the nutritional requirement of $97.5 \%$ of the healthy population. For certain

\begin{tabular}{ll}
\hline KARGER & ( ) 2001 S. Karger AG, Basel \\
Fax +41613061234 & 0250-6807/01/0453-0091\$17.50/0 \\
$\begin{array}{l}\text { E-Mail karger@karger.ch } \\
\text { www.karger.com }\end{array}$ & $\begin{array}{l}\text { Accessible online at: } \\
\text { www.karger.com/journals/anm }\end{array}$
\end{tabular}

Prof. Dr. med. Klaus Schümann

Walther-Straub-Institut für Pharmakologie und Toxikologie

Nussbaumstr. 26, D-80336 München (Germany)

Tel. +49 895160 7223, Fax +498951607207

E-Mail k.schuemann@lrz.uni-muenchen.de 
micronutrients beneficial health effects are observed at intake levels that exceed requirement extensively. For example, selenium and vitamin E seem to counteract free radical damage. Thus, to optimize health it may be desirable to consume such micronutrients in excess of the RDA. This development urges regulatory agencies to establish an 'upper level' (UL) to mark the borderline between favorable health effects and toxicity. The first step in this process is hazard identification, i.e. to spot adverse effects that may lead to persistent impairment of important physiological functions. The next step is to derive a dose-response relationship for such adverse effects and to estimate a 'no adverse effect level' (NOAEL) or a 'lowest adverse effect level' (LOAEL) from available data. An UL can be derived on this basis by use of appropriate safety factors and uncertainty factors. These factors make provisions for sensitive subpopulations and for doubts regarding the reliability of available data [1].

Dose-response assessments for iron present several problems. Firstly, bioavailability of nonheme iron varies by a factor of 10, depending on the composition of the diet [2]. In addition, heme iron absorption is substantially higher than that of nonheme iron. It contributes 20-35\% to total iron intake [3] corresponding to $1-5 \mathrm{mg} \mathrm{Fe} /$ day, which is a considerable range of variation. Due to these uncertainties, it is difficult to assess absorbed iron quantitites at known intake levels. This problem is circumvented by relating the endpoints of iron toxicity to the iron status of the organism.

\section{Rationale behind RDAs and Corresponding Recommendations of the Deutsche Gesellschaft für Ernährung for Dietary Iron Intake}

Iron deficiency anemia affects an estimated $25 \%$ of infants worldwide and up to $46 \%$ of children $>8$ months of age in Guatemala [4]. Children with iron deficiency anemia run a higher risk of an insufficient psychomotor development and impaired cognitive performance [5]. Reduced $\mathrm{O}_{2}$ supply and cytochrome activity lead to reduced physical performance and low birth weight babies [6]. Therefore, the RDA should be high enough to replace the body's iron losses and to fulfil physiological requirements, especially during growth and pregnancy.

A $70 \mathrm{~kg}$ male loses approximately $1 \mathrm{mg} \mathrm{Fe} /$ day with desquamated epithelial cells. Assuming a 10\% absorption rate, an intake of approximately $10 \mathrm{mg} \mathrm{Fe}$ is needed to replace these basal losses. Menstrual iron losses are below
$1.6 \mathrm{mg} \mathrm{Fe} /$ day in $95 \%$ of women. Added to basal losses this leads to an average total loss of approximately $2.5 \mathrm{mg}$ $\mathrm{Fe} /$ day [6]. Assuming an absorption rate of $10-20 \%$ in iron deficiency, an RDA of $15 \mathrm{mg} \mathrm{Fe} /$ day for women of reproductive age is derived. During the 1 st year of life the body requires approximately $260 \mathrm{mg}$ of iron for metabolism and growth, i.e. $0.6-0.8 \mathrm{mg} \mathrm{Fe} /$ day, corresponding to a dietary intake of $6-8 \mathrm{mg} \mathrm{Fe} /$ day per infant. This is the rationale for the RDA value of $1 \mathrm{mg} \mathrm{Fe} / \mathrm{kg}$ body weight for children between the 4th month and 3rd year of life. A total intake of $15 \mathrm{mg} \mathrm{Fe} /$ day is not to be exceeded in infants. During pregnancy, $450 \mathrm{mg} \mathrm{Fe}$ are needed for the mother's increased erythropoiesis, 270-300 and 50$90 \mathrm{mg}$ are transferred to fetus and placenta, respectively, amounting to an extra demand of 770-840 mg. This demand corresponds to approximately $3 \mathrm{mg} \mathrm{Fe} /$ day and to an intake of $30 \mathrm{mg} \mathrm{Fe} /$ day which is the rationale for the recommended higher iron intake in pregnancy. It may be a problem for risk management when it comes to avoid iron overload for those segments of the population with low iron requirements and, at the same time, to supply enough iron to those with a high demand. In the USA, RDAs are exceeded by actual dietary iron intake in males and they are nearly met in females; the prevalence of iron deficiency anemia is as low as $2.5-4.0 \%$. These data show that the RDAs and corresponding recommendations of the DFG are solidly based and that iron deficiency in industrialized countries has become less of a general health problem. This is in part due to a diet favorable for iron bioavailability and partly to the mechanisms of iron homeostasis.

\section{Regulation of Intestinal Iron Absorption}

Depending on its weight the iron-adequate human body contains $2.2-3.8 \mathrm{~g}$ of iron (distribution see table 1 ) [7]. Intestinal iron absorption is geared to the demand via adaptation of a specific receptor population in the duodenal brush border membrane (BBM) [8]. The iron supply from the blood to the immature enterocytes in the duodenal crypts modulates cellular iron-regulating protein (IRP) activity (details see below) which, in turn, seems to regulate the expression of a divalent metal transporter (DMT-1) in the BBM. This process gears nonheme iron uptake from the intestinal lumen to the body's iron requirements [9]. A second mechanism seems to modulate the function of DMT-1 in the BBM and the dislocation of this carrier from the membrane in response to recent iron absorption, which corresponds to a mucosal 
block [10]. Duodenal nonheme iron absorption is further modulated by the iron-regulated transporter at the basolateral membrane of duodenal enterocytes (IREG) [11]. Body iron stores also influence the expression of a BBM reductase that reduces ferric food iron to the ferrous form to make it available to DMT-1. Heme iron, in contrast, is not taken up via DMT-1 but passes the BBM as an Feporphyrin complex [12] either by virtue of its lipophilicity or by use of a putative heme carrier. Heme iron, thus, circumvents downregulation of the bottle neck for nonheme iron absorption in iron overload. The porphyrin ring is cleaved by heme oxygenase in the enterocytes [13]. The released iron enters the enterocytes' nonheme iron pool. Although there is some adaptation of heme binding to the BBM [14] and of heme oxygenase activity, downregulation of heme iron absorption at adequate supply levels is by far not as effective as that of nonheme iron absorption [15].

In humans, nonheme iron absorption from food increases markedly in a situation of increased demand. A 4and 9-fold increase was found in blood donors and in pregnant women, respectively $[15,16]$. When iron stores are repleted, noheme iron absorption goes down and balances basal iron losses at normal dietary intakes [15]. However, although the percentage of iron absorption decreases, administration of high amounts of iron inevitably results in the absorption of higher amounts of iron [17]. Especially, downregulation of intestinal iron absorption in response to preceding iron administration [mucosal block; 10] does not seem to work effectively in humans. Thus, increases in plasma iron concentrations after oral intake of $75 \mathrm{mg}$ Fe were similar to the increase after a second and third dose given on the same day [18]. When iron was given with the meal - corresponding to the situation of food fortification - 2.6\% (1.3 mg Fe) were absorbed from a single dose of $50 \mathrm{mg} \mathrm{FeSO}_{4}$. When $50 \mathrm{mg}$ $\mathrm{Fe} /$ day were given for a week (350 mg Fe), absorption was $2.3 \%$ ( $8.0 \mathrm{mg} \mathrm{Fe})$, showing no blocking effect of preceding iron doses [19]. Also, the absorption rate (8.9\%) after $60 \mathrm{mg} \mathrm{Fe} /$ day for 6 days (total intake $360 \mathrm{mg} \mathrm{Fe}$ ) was in the same order of magnitude as after intake of $120 \mathrm{mg} \mathrm{Fe}$ once weekly for 3 weeks (10.9\%) [20]. When nonheme iron absorption was as low as $2 \%$, heme iron absorption was still as high as $15 \%$ [15] showing that downregulation of heme iron absorption in response to increasing iron stores is even less effective than that of nonheme iron in humans. Iron excretion is not regulated. At normal intake levels about $1 \mathrm{mg} \mathrm{Fe}$ /day is lost with the desquamated enterocytes, corresponding to as little as $0.025-0.05 \%$ of body iron content. The examples show that downregula-
Table 1. Distribution of body iron content [data taken from 7]

\begin{tabular}{|c|c|c|c|c|}
\hline & \multicolumn{2}{|l|}{ Males } & \multicolumn{2}{|c|}{ Females } \\
\hline & $\mathrm{mg}$ & $\mathrm{mg} / \mathrm{kg} \mathrm{BW}$ & $\mathrm{mg}$ & $\mathrm{mg} / \mathrm{kg} \mathrm{BW}$ \\
\hline \multicolumn{5}{|l|}{ Functional iron } \\
\hline Hemoglobin & 2,300 & 31 & 1,700 & 28 \\
\hline Myoglobin & 320 & 4 & 180 & 3 \\
\hline Heme enzymes & 80 & 1 & 60 & 1 \\
\hline Nonheme enzymes & 100 & 1 & 76 & 1 \\
\hline \multicolumn{5}{|l|}{ Iron stores } \\
\hline Ferritin & 700 & 9 & 205 & 3 \\
\hline Hemosiderin & 300 & 4 & 90 & 1 \\
\hline Total & 3,800 & 50 & 2,200 & 37 \\
\hline
\end{tabular}

tion of intestinal iron absorption may not be sufficient to protect from iron overload and that dietary intake levels have to be adapted accordingly. Moreover, adaptation of intestinal iron absorption works to an even smaller extent in heterozygotes for hereditary hemochromatosis [21], who make up approximately $10 \%$ of the population of North-European origin.

High iron contents in the diet will decrease $\mathrm{Zn}$ absorption which, however, needs pharmaceutical iron doses [22]. The iron impact on $\mathrm{Cu}$ absorption is even less pronounced.

\section{Iron Homeostasis}

Excess iron is sequestered into ferritin, from where it can be mobilized when demand increases. A small family of messenger RNAs is equipped with specific base loops (iron-responsive element, IRE) that bind to IRP in the cytosol. Binding of IRP to the IRE in the $5^{\prime}$ untranslated region (UTR) of the mRNA represses ferritin translation; binding to multiple IREs in the $3^{\prime} \mathrm{UTR}$, in contrast, stabilizes the mRNA of the transferrin receptor. The IRP-IRE affinity is increased in iron-deficient cells (fig. 1). This mechanism modulates the expression of ferritin and transferrin receptors and, thus, regulates the availability of low molecular iron in the cells [23]. Unfortunately, the same mechanism will also mobilize iron from ferritin and import it via transferrin receptors in situations of oxidative stress. Nitric oxide and superoxide radicals increase the IRP-IRE affinity [24]. Thus, cells under oxidative stress are likely to behave as in iron deficiency: they can release iron from the stores and increase iron uptake from the extracellular space (fig. 1). This misguided process 


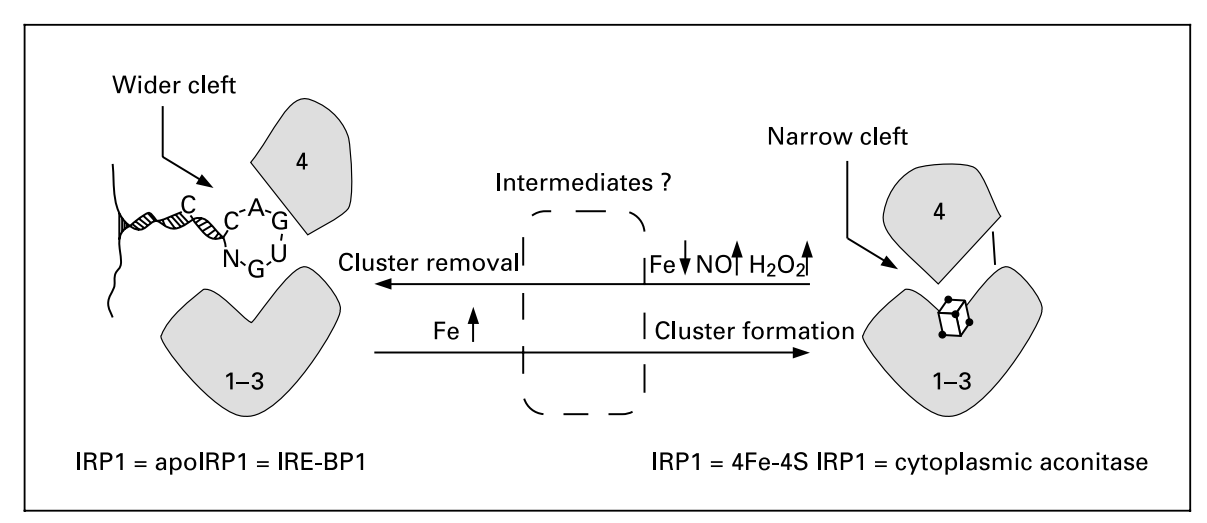

Fig. 1. Function of the IRP 1. IRP-1 is a bifunctional cytoplasmic protein with a molecular mass of $98 \mathrm{kD}$. In iron-deficient cells the protein loses a cuban $4 \mathrm{Fe}-4 \mathrm{~S}$ cluster and a wide cleft forms between the domains 1-3 and domain 4. This apoprotein binds to IREs which are specific base loops at the $3^{\prime}$ UTR of the transferrin receptor mRNA and at the $5^{\prime}$ UTR, e.g. of the ferritin mRNA. IRP-binding stabilizes the transferrin receptor mRNA which increases transferrin receptor expression and cellular iron import. Binding to the IREs at the $5^{\prime}$ UTR destabilizes the ferritin mRNA and decreases cellular iron sequestration. Both events should increase free iron in the cytosol, leading to new cluster formation in the IRP and a narrow cleft. In this situation the protein shows aconitase activity and does not bind to IREs. An 'opened' conformation with sufficient space in the cleft is also observed at high $\mathrm{NO}$ and $\mathrm{H}_{2} \mathrm{O}_{2}$ concentrations. $\mathrm{C} 437$ appears to be the critical cysteine residue which accounts for the sensitivity of IRP-1 to redox manipulation [taken from 89]. may amplify oxidative stress. Besides, homeostasis can be overwhelmed by excess iron intake. In all these situations, iron may cause substantial harm to the body, depending on dose and duration of excess iron exposure.

\section{Damage after Acute Iron Exposure}

Ingestion of an acute overdose of pharmaceutical iron preparations is known to cause local corrosion in the stomach and upper small intestine. High absorbed iron quantities cause shock symptoms due to postarteriolar dilatation, capillary leakage and heart failure. High iron concentrations damage hepatic mitochondria, leading to liver cell necrosis with bleeding disorders and hepatic failure. Though the mortality rate from iron intoxication increased from 0.05 before 1990 to 0.116 per 100 patients exposed to iron preparations in 1991 [25], it is overall a rare event. An oral dose of 180-300 mg Fe/kg body weight can be lethal. Oral doses below 10-20 mg Fe/kg body weight are regarded as nontoxic for humans [26], leading to a NOAEL of $10 \mathrm{mg} \mathrm{Fe} / \mathrm{kg}$ body weight for acute iron toxicity. This is far beyond the dose range of dietary iron exposure.

At therapeutic dose levels a series of side effects of oral iron preparations due to irritation of the gastrointestinal mucosa were observed, including nausea, vomiting, heartburn and epigastric discomfort. Along with diarrhea and obstipation, these side effects were observed in about $25 \%$ of patients after administration of $100 \mathrm{mg} \mathrm{Fe} /$ day in a placebo-controlled study [27]. An earlier study found the same side effects at $180 \mathrm{mg} /$ day. If $100 \mathrm{mg} \mathrm{Fe} /$ day is taken as LOAEL, a safety factor of 2 leads to an USL of $50 \mathrm{mg}$ $\mathrm{Fe} /$ day for mucosal irritation by nonheme iron salts. Reddajah et al. [28] described gastrointestinal side effects at doses of $50 \mathrm{mg} \mathrm{Fe} /$ day in non-placebo-controlled study. Thus, the USL for this effect should be below $50 \mathrm{mg} \mathrm{Fe} /$ day, e.g. 30-40 mg Fe/day. One has to consider, though, that the 'daily intake' was taken as a single dose of iron salt in these studies. This is different from dietary intake and limits the value of these data for extrapolation to food iron.

\section{Chronic Iron Overload}

Hazards can also be identified for excessive chronic iron ingestion. Symptoms such as hepatomegaly, joint inflammation, diabetes mellitus, cardiac failure or hepatoma are possible sequels of parenchymal iron overload. Excess iron is a major factor in the progression of hepatic fibrosis at concentrations above $400 \mu \mathrm{mol} \mathrm{Fe} / \mathrm{g}$ dry weight. Patients who ingested $160-1,200 \mathrm{mg} /$ day pharmaceutical iron over more than a decade developed secondary hemochromatosis and died of cirrhosis, diabetes or cardiac failure [29]. Such cases are inappropriate to 
derive a LOAEL or NOAEL, as they deal with excessively high intakes and did not exclude hereditary hemochromatosis.

Homozygotes for hereditary hemochromatosis are a highly sensitive subpopulation for iron overload. This disease is caused by a defect in the HLA (HFE) gene which increases iron absorption 2- to 3-fold. It is observed in $0.3-0.5 \%$ of the Caucasian population. The male/female ratio among homozygotes is $1: 1$; for serious manifestations it is about 5:1, though, if untreated. This is because women have constantly higher iron losses via menstrual bleeding. In hereditary hemochromatosis, transferrin saturation is frequently close to $100 \%$. Free, bleomycindetectable iron is often present and parenchymal cells can be damaged, e.g. by Fenton chemistry.

Bantu siderosis is caused by excess oral iron intake with home-brewed beer, fermented in iron drums in subSaharan Africa. Regular consumption of such beer may serve as a model for chronic dietary iron overload, leading to hepatic cirrhosis and diabetes. The bioavailability of such iron is high. It parallels that of $\mathrm{FeCl}_{3}$ salts and is approximately one third of that of $\mathrm{Fe}^{2+}$ salts. The average intake in the patients was 50-100 mg Fe/day [30]. A cumulative excess intake of approximately $28 \mathrm{~g}$ Fe was derived as a threshold for the development of fibrosis. The average consumption seems to have been less than 2 liters of beer/day which is too little for clear-cut alcoholism. Still, substantial alcohol intake in some patients might have supported the development of cirrhosis. Iron absorption in cirrhotic subjects was not higher than in healthy controls [30], although a genetic failure distinct from HLA-linked hemochromatosis was later discussed to have increased intestinal iron absorption [31]. These findings lead to a LOAEL of 50-100 mg Fe to cause cirrhosis in the long run. Applying a safety factor of 2 seems sufficiently conservative, because we deal with a putatively sensitive subpopulation, for which a genetic disposition and alcohol intake are discussed. Therefore, a USL of 25$50 \mathrm{mg} \mathrm{Fe} /$ day should be derived from these data.

\section{Iron, Increased Oxidative Damage and Cardiovascular Risk}

In 1992 Salonen found marginally increased iron stores to be related to an excess risk of acute myocardial infarction (AMI). These data supported Sullivan's iron hypothesis [32] on the increased cardiovascular risk from 1981 which was based on three observations. (1) In parallel to higher iron stores, men have a higher risk of AMI

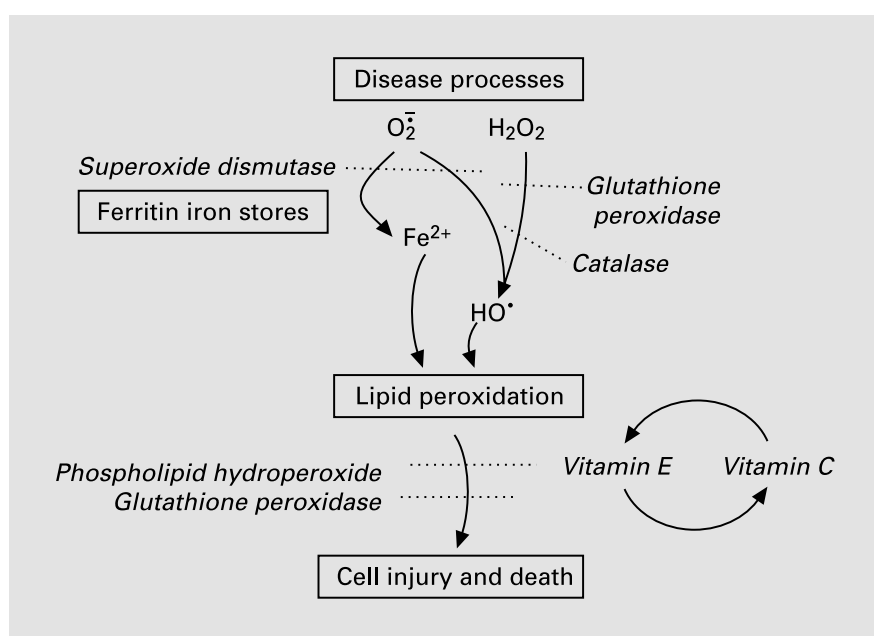

Fig. 2. Impact of iron on the metabolism of active oxygen species. Active oxygen species $\left(\mathrm{O}_{\overline{2}}^{\circ}\right.$ and $\left.\mathrm{H}_{2} \mathrm{O}_{2}\right)$ lead to the mobilization of stored iron, to lipid peroxidation and to cell injury and death. The antioxidant enzymes and vitamins (shown in italics) and their points of intervention in the process are indicated by dotted lines [taken from 35].

than premenopausal women, (2) hysterectomized women have an increased risk of AMI, implying that some risk modification is due to the absence of menstrual blood losses and not to reduced estrogen production, and (3) people from developing countries have less AMI which, again, is in parallel to low body iron stores. Epidemiological studies on the relationship between iron stores and cardiovascular risk are still controversial. However, evidence in favor of the iron hypothesis has become so substantial that it cannot be ignored when the impact of iron on human health is discussed.

\section{Molecular Aspects}

Iron participates in a complex pathophysiological mechanism that is supposed to increase oxidative stress and cardiovascular risk. Superoxide anions are produced e.g. as a by-product of mitochondrial energy metabolism, by xanthine oxidation or by neutrophils and macrophages in inflamed tissues [33]. Such superoxide anions are transformed by superoxide dismutase, by glutathione peroxidase and catalase to $\mathrm{H}_{2} \mathrm{O}_{2}$ and finally to $\mathrm{H}_{2} \mathrm{O}$ which forms a potent defense against oxidative stress (fig. 2). However, superoxide anions can alternatively be converted to form highly reactive hydroxyl radicals by iron mediated Fenton chemistry (see Appendix) which potentiates local oxidative stress, e.g. in mitochondria. Chelation of iron by small endogenous ligands like citrate and ADP are no 
obstacle for the oscillation of iron between $\mathrm{Fe}^{2+}$ and $\mathrm{Fe}^{3+}$ which is the driving force of Fenton chemistry. One hydroxyl radical can go through 10-15 reaction cycles and destroy lipid membranes, proteins and cause DNA strand breaks [34]. Thus, one hydroxyl radical will produce 1015 chain reaction seeds before it is stopped by radical scavengers, e.g. $\alpha$-tocopherol, lycopene or $\beta$-carotene, which are consumed in the process and must be regenerated or replaced (fig. 2) [35].

Because of these mechanisms, the question of what quantity of iron in the body is safe is closely related to the question of which conditions disturb the equilibrium between pro- and antioxidative mechanisms. In principle, such disturbances can, firstly, be caused by an increased basal generation rate of reactive oxygen species (ROS). This is observed under pathological conditions, such as inflammation and ischemia/reperfusion injury. Secondly, local iron availability will aggravate oxidative stress of any origin via Fenton chemistry. As excess iron cannot be excreted from the body, it is either incorporated into heme to serve specific functions or it is sequestered and stored in ferritin. Hemeoxygenase 1 is induced in ischemia and liberates iron form heme [36]. Iron can also be liberated from ferritin under oxidative stress [37]. In addition, oxidative stress increases intracellular free iron concentration via IRP activation (fig. 1), which promotes the conversion of less reactive to more reactive radicals. Thirdly, the cell may run out of radical scavengers due to increased consumption under oxidative stress. In all 3 cases the equilibrium is shifted substantially to the prooxidative side.

Free iron seems to play a crucial role in the amplification of oxidative stress. The process is a self-amplifying vicious circle. There is no place in the organims, neither in ferritin nor in the heme-bound form, where excess iron can be safely stored to prevent Fenton reaction from occurring. A possible exception is hemoglobin-bound iron in erythrocytes, because these cells have highly developed intrinsic antioxidative defense mechanisms. Thus, excess iron stores can be compared to a powder keg: it is not wise to carry a higher supply than needed for necessary requirements.

\section{Iron-Promoted Oxidative Stress on the Organ Level}

If these mechanistic considerations are valid, substitution or chelation of free iron should influence free radical production in ischemia-reperfusion injury. On the organ level, it should modulate lipid peroxidation and impair organ function. Indeed, all these effects were observed in corresponding animal experiments and clinical observa- tions. The iron concentration in coronary flow fractions increased with the duration of ischemia in isolated rat hearts and cardiac contraction was impaired correspondingly [38]. Also, administration of the iron chelator desferrioxamine (DFO) before surgical occlusion of the coronaries reduced the increment in free radical activity to $113 \%$ as compared to $136 \%$ in controls without DFO [39]. Administration of DFO to dogs before coronary occlusion impaired myocardial function to a lesser degree than without DFO [40] and ventricular pressure in isolated rabbit hearts was less attenuated [41]. Exocholine is a new lipophilic iron chelator. It reduced hydroxyl radical concentration and restored coronary flow rates and systolic pressure performance in isolated rabbit hearts after coronary occlusion [42].

DFO administration before bypass operations in humans reduced the superoxide anion concentration in neutrophilic leukocytes, diminished mitochondrial swelling and chemiluminescence for ROS in myocardial biospies and lipid peroxidation. In experimental claudicatio intermittens of rat hind limbs, parameters for lipid peroxidation increased significantly less after DFO administration [43] and carotid blood flow, cerebral $\mathrm{O}_{2}$ metabolism and electrocortical activity were significantly less impaired in experimental asphyxia of newborn lambs. A similar positive effect on the cerebrum was seen after allopurinol administration which reduces xanthinoxidase and, thus, ROS generation [44]. Administration of DFO before hepatic ischemia as a model for the ischemic phase in liver transplantation decreased lipid peroxidation and $\mathrm{TNF} \alpha$ release from Kupffer cells as well as morphological damage $[45,46]$.

The above findings support a causal relationship between available free iron and the generation of free radicals on the one hand and the extent of functional impairment and morphological damage on the other. Unfortunately, DFO has a comparably short half-life, penetrates slowly across lipid membranes and depresses cardiovascular function at high concentrations [47]. Therefore, the usefulness of this chelator in the therapy of cardiovascular diseases is limited. Still, to reduce free iron seems beneficial in ischemia-reperfusion events, implying that high iron stores are disadvantageous and may aggravate the sequels of such events.

\section{Epidemiological Studies on the Impact of Iron Status on AMI Risk}

Salonen et al. [48, 49] found a 2.2-fold increased risk of AMI in Eastern Finnish males at serum ferritin levels of $>200 \mu \mathrm{g} / \mathrm{l}$. An additional intake of $1 \mathrm{mg} \mathrm{Fe} /$ day was 
calculated to increase the cardiovascular risk by $5 \%$. These assumptions have been criticized insofar as the impact of inflammatory diseases on serum ferritin should have been controlled more rigidly and the relationship between circulating ferritin and AMI risk should have been pursued for the whole range of values. Besides, it was argued that heterozygotes for hemochromatosis with their slightly increased average iron stores should have an increased cardiovascular risk as well, if a ferritin value of $>200 \mu \mathrm{g} / \mathrm{l}$ were to increase that risk. This had, indeed, not been observed at that time; however, all of these requirements were fulfilled in the more recent studies on the subject as reported below.

No association was found between cardiovascular risk, on the one hand, and serum iron concentrations, transferrin saturation and total iron binding capacity (TIBC), on the other hand, in two subsequent studies [50, 51]. A transferrin saturation $>60 \%$, however, accompanied an increased risk of AMI which fell short of statistical significance [51]. Serum ferritin did not seem to be associated with a cardiovascular risk in a study from Iceland [52], although the risk was increased in people with low TIBC representing high iron stores. Diets high in highly bioavailable heme iron increased the cardiovascular risk, but went along with high fat and cholesterol intake as well [53]. Morrison et al. [54] found a significantly increased risk of AMI at serum iron concentrations of $>175 \mu \mathrm{g} / \mathrm{dl}$, which supports the iron hypothesis.

Most of these follow-up studies published between 1994 and 1997 did not support the findings of Salonen et al. However, they raised concern about the choice of adequate biomarkers to define body iron stores. Serum iron concentrations and transferrin saturation represent no advantage over ferritin concentration; on the contrary, they are much more variable [55]. Other authors complained about a confusing and inadequate design in some of these studies, failure to exclude subjects with hepatic or inflammatory diseases and inappropriate methods to determine iron stores [56, 57]. There were calls for prospective studies using adequate parameters to define iron status [55].

The most recent generation of studies tried to fill this gap. Klipstein-Gobush et al. [58] found an 1.8-fold increased risk of AMI at serum ferritin values of $>200 \mu \mathrm{g} / \mathrm{l}$. The risk increased 1.3-fold with every next tercile of serum ferritin increments. A high intake of heme iron increased the AMI risk 2.7-fold. Serum iron, transferrin saturation and dietary iron intake did not correlate with AMI risk, showing that these parameters are, indeed, less appropriate than serum ferritin. Liver enzymes were con- trolled to exclude hepatic damage. Inflammation was controlled by determination of C-reactive protein and leukocytes at the beginning of the study to rule out chronic inflammatory diseases at that point in time. Acute diseases that made the patient see a GP were registered by the protocol and verified by research physicians. Erythrocyte sedimentation rates were determined to establish whether earlier inflammatory processes had faded off though they may have increased ferritin before. Alcohol intake as confounding factor for serum ferritin increases was accounted for. A Finnish study [59] used the ratio between serum transferrin receptor concentration (TfR) and serum ferritin which seems to represent the diagnostic optimum to define body iron stores. TfR is largely independent of inflammatory influences, decreases with increasing iron stores and is most sensitive when iron stores are low, while ferritin is more sensitive at high body iron stores. If serum ferritin were high due to inflammation in spite of low iron stores, TfR would go up. Therefore, parallel determination of both parameters reduces the risk of misinterpreting high ferritin values due to inflammation as an indicator of high iron stores. At ferritin concentrations over $200 \mu \mathrm{g} / \mathrm{l}$ AMI risk was 2.5 times higher and increased 2.0-fold with every next tercile of ferritin increment. An additional dietary intake of $1 \mathrm{mg}$ $\mathrm{Fe} /$ day increased the AMI risk by $8.4 \%$. Analyzing body iron stones by terciles suggests a continuum of this parameter on the AMI risk. This is supported by a decreased AMI risk in blood donors, who have low body iron stores $[60,61]$. The latter study controlled the health of donors and nondonors alike to be comparable. Another trial showed significantly higher serum ferritin values in coronary artery disease patients with an early onset (age $<46$ years) as compared to others with a late onset (age $>74$ years) [62]. The most recent and best-controlled epidemiological studies, thus, support the iron hypothesis of increased cardiovascular risk. However, to finally prove the causal association, an intervention trial would be needed; this would be highly unethical in the light of the available data.

\section{AMI Risk in Heterozygotes of Hereditary \\ Hemochromatosis}

Due to slightly increased iron absorption, $25-30 \%$ of heterozygotes have elevated iron stores. The iron excess is available early in life [63], which might increase cardiovascular risk. Indeed, there seems to be a family aggregation of hereditary cardiovascular risk in $5-7 \%$ of the male population that cannot be explained by conventional risk factors such as diabetes and hypertension [56]. In a pro- 
spective nested case control study in 11,631 subjects, 531 cardiovascular patients were compared to 535 controls that died of other causes. Among the cardiovascular deaths, $7.2 \%$ were heterozygous for hemochromatosis as compared to $4.1 \%$ in controls. In controls, hypertension and smoking increased cardiovascular risk by $2.2 \%$ as compared to $40.0 \%$ in heterozygotes [64]. This risk increment should be due to extra iron, because this is what characterizes the heterozyotes. The self-amplifying effect of iron on ROS production described on the molecular level is likely to be the responsible mechanism.

In a prospective cohort study in 1,150 Finnish males $6.7 \%$ were found to be heterozygous for hemochromatosis [65]. $10.4 \%$ of heterozygotes had myocardial infarction as compared to $5.6 \%$ in the control population. Again, smoking increased the risk significantly. An increment in serum ferritin of $100 \mu \mathrm{g} / 1$ increased the AMI risk by $52 \%$. These results take away one of the most severe objections to the iron hypothesis of the cardiovascular risk, namely that heterozygotes are not affected.

\section{Iron Stores and Atherosclerosis}

High iron concentrations were found in human atherosclerotic lesions [66]. $\mathrm{Fe}^{+}$and $\mathrm{Cu}^{2+}$ increase local concentrations of hydroxyl radicals which are supposed to oxidize surface structures of LDL. According to current understanding this oxidation increases LDL affinity to macrophage scavenger proteins and accelerates foam cell formation in the vascular endothelium, which causes cytotoxic endothelial injury via chemotactic mechanisms. This process facilitates the entry of lipoproteins into the intima, leading to smooth muscle cell proliferation and the development of atherosclerotic plaques [57]. In agreement with this concept, the iron content was higher in atherosclerotic lesions in apolipoprotein-E-deficient mice. In iron deficiency serum ferritin was reduced by one third and the iron content in atherosclerotic lesions decreased accordingly. This was paralleled by a reduction in number and size of the lesions and reduced immunostaining for epitopes of oxidized LDL [67]. Local Fenton chemistry in the atherosclerotic plaques would also explain the lack of an association between serum ferritin levels and measures of LDL oxidation in human blood [68].

Sonographic assessment of carotid atherosclerosis was correlated with iron stores in 847 persons aged between 40 and 79 years. Hypercholesterinemia increased the lesions synergistically. The odd rate increased 1.5 -fold with each increment of $100 \mu \mathrm{g} / \mathrm{l}$ in serum ferritin [69]. In a follow-up study, the risk of developing new atherosclerotic lesions was correlated with body iron stores. Inflamma- tion and cancer were excluded in these patients. Serum iron and transferrin saturation were weak predictors. Progression of late atherosclerosis was not related to iron stores [57].

\section{Iron and Cancer}

\section{Molecular Mechanisms}

Iron has been suggested to induce cancer by oxidative damage of DNA. Renal adenocarcinoma induction in rats [70] after intraperitoneal injection of Fe-nitrilotriacetic acid (Fe-NTA) supports this notion. In contrast to intraperitoneally applied ferric succhrate, which is insoluble and induces local peritoneal mesothelioma [71], soluble Fe-NTA is absorbed by the peritoneum and circulates in the blood. After glomerular filtration iron finds an optimal environment for the Fenton reaction in the lumen of the proximal renal tubules. At this location, lipid peroxidation turned out to be clearly associated with the induction of renal cancer [72]; both could be significantly reduced by vitamin $\mathrm{E}$ administration [73]. Chelated $\mathrm{Fe}^{3+}$ effectively catalyzed DNA single and double strand breaks producing 8 -OHGua as a maker for oxidative DNA damage [74] and interstrand cross-links by site-specific mechanisms [34]. Induction of lung cancer after asbestos inhalation relates to the iron content of different asbestos fibers [75] and iron and nitric oxide seem to be necessary for the mutagenic action of asbestos fibers [76]. Moreover, a high iron supply supports tumor cell proliferation [77]. Ample iron supply is likely to promote tumor growth whereas iron restriction can reduce cancer induction [78]. As a defense against iron-induced oxidative stress human tumor cells produce glutathione S-transferase pi. These mechanisms explain promoting effects of iron on dimethylnitrosamine- and dimethylbenz(a)anthracene-induced tumors in animal experiments [79]. Oxidative stress, moreover, may accelerate the conversion of precarcinogens to carcinogens [80].

\section{Epidemiological Observations}

Stevens et al. [81] first reported an association between iron stores and cancer; this was criticized because of the small differences in transferrin saturation $(+2.4 \%)$ and TIBC $(-1.5 \%)$ between cancer and noncancer groups. Also, the risk of cancer induction was not stratified according to different periods of follow-up duration. It was suspected that these iron status indicators have been increased as a consequence of cancer that was present at the start of the study [82]. This objection was overcome by 
longer follow-up periods, after which the correlation between high iron stores and cancer was still present [83]. In addition, a dose-response relationship between transferrin saturation and relative risk of cancer was derived. The risk increased progressively at transferrin saturation levels above $40 \%$. The cancer frequency in esophagus, bladder and in the colorectal area increased in parallel to iron stores. Dietary phytates, themselves known to decrease iron availability, seem to protect the colon from lipid peroxidation, which is in agreement with these observations [84]. In contrast, the frequency of stomach cancer decreased with iron status, because induction of this tumor is frequently associated with low gastric acidity leading to low iron absorption [83]. Knekt et al. [85] found the risk of colorectal and lung cancer to be related with increased iron stores. Again, differences in iron status between cancer and noncancer groups were small. The role of iron in cancer promotion is supported by the therapeutic effect of iron chelators in the therapy of neuroblastoma [86] and by reports on a reduced cancer risk in blood donors [87].

Promotion of tumor growth after iron supplementation in animals seems a very reproducible finding. A causal relationship between cancer promotion, possibly also between cancer induction and iron stores, is likely but not firmly proven for humans. On this database, an intervention trial in humans to prove or disqualify this issue would be clearly unethical and iron supplementation beyond the RDA requirements cannot be recommended.

\section{Safety of Iron in Food}

Food safety tries to avoid deficiency states as well as the risks of excess intake; additional aspects of food safety, like allergy, microbial or toxic contamination and the impact of food additives or agrochemicals shall not be discussed here, although cadmium, lead, nickel, cobalt and plutonium may accumulate in the body to a greater extent in iron deficiency, as these metals partly share the absorptive pathways of iron which is negatively correlated with iron stores [88]. However, there is no regulated iron excretion in situations of dietary overload. To avoid adverse effects, therefore, iron intake should not exceed these metabolic requirements. Excess intake of pharmaceutical iron preparations may lead to acute toxicity and secondary hemochromatosis. At therapeutic dose levels they cause side effects. This is of limited relevance to assess the risk of dieteary iron, though it helps to characterize possible hazards. Chronic excess intake of highly available iron with a food item was observed in Bantu siderosis, where chronic intakes between 50 and $100 \mathrm{mg}$ Fe/day caused live cirrhosis, diabetes and heart failure. Applying a safety factor of 2 would lead to an USL of $25-50 \mathrm{mg} \mathrm{Fe} /$ day for conventional iron toxicity as an endpoint.

However, reports on an association between iron stores and cardiovascular and cancer risk urge to extend the database for risk assessment. The molecule mechanisms of how iron accumulates in specific tissues under oxidative stress and amplifies it are known. In this perspective the question of how much iron is safe needs to be rephrased. We should ask to what extent we can rely on antioxidative mechanisms to prevent cardiovascular diseases and cancer as sequels of iron-amplified oxidative stress. In healthy humans, the answer is stochastic; in the vast majority of cases, antioxidative defense is sufficient. However, high iron stores seem to shift the odds for the worse as is suggested by the more recent, intensely controlled epidemiological studies [58, 59, 64, 65]. Looking at animal experiments and clinical data, the balance between oxidative stress and antioxidative defense seems clearly disturbed in ischemia-reperfusion damage. There is profound evidence that iron-amplified oxidative stress participates in the pathophysiology of AMI, stroke and cancer, which are the most common causes of death in the industrialized countries. Even though the issut is not finally settled, available data do suggest that the UL should not be set beyond the RDA, i.e. not beyond the requirement of growth and metabolic demand. These, however, must be met to avoid deficiency symptoms. The same rationale applies for pharmaceutical iron substitution under medical supervision, e.g. to replete iron losses after bleeding.

\section{Appendix}

$$
\begin{aligned}
& \mathrm{Fe}^{2+}+\mathrm{H}_{2} \mathrm{O}_{2} \rightarrow \mathrm{Fe}^{3+}+\mathrm{OH}^{-}+\mathrm{HO}^{\bullet} \\
& \frac{\mathrm{O}_{2}^{\bullet}+\mathrm{Fe}^{3+} \rightarrow \mathrm{O}_{2}+\mathrm{Fe}^{2+}}{\mathrm{O}_{2}^{\circ}+\mathrm{H}_{2} \mathrm{O}_{2} \rightarrow \mathrm{O}_{2}+\mathrm{OH}^{-}+\mathrm{HO}^{\bullet}}
\end{aligned}
$$

Superoxide may dismutate to form hydrogen peroxide and the hydroxyl radical $\left(\mathrm{HO}^{\circ}\right)$ by Fenton and Haber-Weiss chemistry. This process is catalyzed by iron which oscillates between its divalent and its trivalent form. The hydroxyl radical is an extremely potent oxidizing species which can depolymerize polysaccharides, cause DNA strand breaks, inactivate enzymes and initiate lipid peroxidation [35].

Ann Nutr Metab 2001;45:91-101 


\section{References}

1 Hathcock JN: Safety limits of nutrition. J Nutr 1996; 126:2386S-2389S.

2 Hallberg L, Rossander L: Improvement of nutrition in developing countries: Comparison of adding meat, soy protein, ascorbic acid, citric acid and ferrous sulfate on iron absorption from a simple Latin American meal. Am J Clin Nutr 1984;39:578-583.

3 Monsen ER, Hallberg L, Layrisse M, Hegsted M, Cook JD, Merz W, Finch CA: Estimation of available dietary iron. Am J Clin Nutr 1978;31: 134-141.

4 Dewey KG, Romero-Abal ME, Quan de Serrano J, Bulux J, Peerson JM, Engle P, Solomons NW: Effects of discontinuing coffee intake on iron status of iron-deficient Guatemalan toddlers: A randomized intervention study. Am J Clin Nutr 1997;66:168-176.

5 Lozoff B, Jemenez E, Wolf AW: Long-term developmental outcome of infants with irondeficiency. N Engl J Med 1991;325:687-694.

6 Baynes RD, Bothwell TH: Iron deficiency. Annu Rev Nutr 1990;10:133-148.

7 Lynch SR: Iron; in Solomons NW, Rosenberg ICH (eds): Absorption and Malabsorption of Mineral Nutrients. New York, Liss, 1984, pp 89-124.

8 Gunshin H, Mackenzie B, Berger U, Gunshin Y, Romero MF, Boron WF, Nussberger S, Gallan JL, Hediger MA: Cloning and characterization of a mammalian proton-coupled metal-ion transporter. Nature 1997;388:482-488.

9 Schümann K, Moret R, Künzle H, Kühn LC: Iron regulatory protein as an endogenous sensor of iron in rat intetinal mucosa. Possible implications for the regulation of iron absorption. Eur J Biochem 1999;260:362-372.

10 Oates PS, Trinder D, Morgan EH: Gastrointestinal function, divalent metal transporter-1 expression and intestinal iron absorption. Pflügers Arch 2000;440:496-502.

11 Mckie AT, Marciani P, Rolfs A, Brennan K Wehr K, Barrow D, Miret S, Bomford A, Peters TJ, Farzaneh F, Hediger MA, Hentze MW, Simpson RJ: A novel duodenal iron-regulated transporter, IREG1, implicated in the basolateral transfer of iron to the circulation. $\mathrm{Mol}$ Cell 2000;5:299-309.

12 Wyllie JC, Kaufmann N: An electron microscopic study of heme uptake by rat duodenum. Lab Invest 1982;47:471-476.

13 Raffin SB, Woo CH, Roost KT, Price DC, Schmid R: Intestinal absorption of hemoglobin iron-heme clevage by mucosal heme oxygenase. J Clin Invest 1974;54:1344-1352.

14 Roberts ST, Henderson RW, Young GP: Modulation of uptake of heme by rat small intestinal mucosa in iron deficiency. Am J Physiol 1993;265:G712-G718.

15 Hallberg L, Hulten L, Gramatkovski E: Iron absorption from the whole diet in men: How effective is the regulation of iron asborption. Am J Clin Nutr 1997;66:347-356.
16 Barrett JFR, Whittaker PG, Williams JG, Lind $\mathrm{T}$ : Absorption of non-haem iron from food during normal pregnancy. Br Med J 1994;309:7982

17 Beutler E: How little we know about the absorption of iron. Am J Clin Nutr 1997;66:419420 .

18 Hallberg L: Oral iron therapy - factors affecting the absorption; in Hallberg L, Harwerth HG, Vanotti A (eds): Iron Deficiency. New York, Academic Press, 1970, pp 551-561.

19 Cook JD, Reddy MB: Efficacy of weekly compared with daily iron supplementation. Am J Clin Nutr 1996;62:117-120.

20 Pizzaro F, Olivares M, Arredondo M, Hertrampf E, Walter T: Does Daily Iron Administration Produce a Mucosal Blockade? Wageningen, European Academy of Nutritional Science, 1997.

21 Powell LW, Jazwinska E, Halliday JW: Primary iron overload; in Brock JH, Halliday JW, Pippard MJ, Powell LW (eds): Iron Metabolism in Health and Disease. London, Saunders, 1994, pp 227-270.

22 Solomons NW: Competitive interaction of iron and zinc in the diet. Consequences for human nutrition. J Nutr 1986;110:927-934.

23 Klausner RD, Rouault TA, Harford JB: Regulation of the fate of mRNA: The control of cellular iron metabolism. Cell 1993;72:19-28.

24 Hentze MW, Kühn LC: Molecular control of vertebrate iron metabolism - mRNA-based regulatory circuits operated by iron, nitric oxide, and oxidative stress. Proc Natl Acad Sci USA 1996;93:8175-8182.

25 Berkovitch M, Matsui D, Lamm SH, Rosa F, Koren G: Recent increases in numbers and risk of fatalities in young children ingesting iron preparations. Vet Hum Toxicol 1994;36:5355.

26 Ellenhorn MJ, Barceloux DG (eds): Iron. Medical Toxicology. New York, Elsevier, 1988, pp 1023-1030.

27 Ganzoni AM, Töndung G, Rhymer K: Orale Eisenmedikation. Dtsch Med Wochenschr 1974:99:1175-1178.

28 Reddajah VP, Prasanna P, Ramachandran K, Nath LM, Sood SU, Madan N, Rusia U: Supplementary iron dose in pregnant anemia prophylaxis. Indian J Pediatr 1989;65:109-114.

29 Green P, Evitan JM, Sivota P, Avidor I: Secondary hemochromatosis due to prolonged iron ingestion. Isr J Med Sci 1989;25:199-201.

30 Bothwell TH, Seftel H, Jacob P, Torrance JD, Baumslag N: Iron overload in Bantu subjects. Am J Clin Nutr 1964;14:47-51.

31 Gordeuk U, Mukiibi J, Hasstedt SJ: Iron overload in Africa. Interaction between a gene and dietary iron control. N Engl J Med 1992;326: 95-100.

32 Sullivan JL: Iron versus cholesterol - Perspectives on the iron and heart debate. J Clin Epidemiol 1996;49:1345-1352.
33 Rosenthal GJ, Germolec DR, Blazka ME, Corsini E, Simenova P, Pollock P, Kong L-Y, Kwon J, Luster MI: Asbestos stimulates IL-8 production from human lung epithelial cells. J Immunol 1994;153:3237-3244.

34 Lloyd DR, Phillips DH: Oxidative DNA damage mediated by copper (II), iron (II) and nickel (II) Fenton reactions: Evidence for site specific mechanisms in the formation of double-strand breaks, 8-hydroxyguanosine and putative instrand cross-links. Mutat Res 1999;424:23-36.

35 McCord JM: Iron, free radicals, and oxidative injury. Semin Hematol 1998;35:5-12.

36 Koishinako J, Miettinen S, Keinänen R, Vartieinen N, Roivainen R, Laitinen JT: Longterm induction of haem oxygenase-1 (HSP-32) in astrocytes and microglia following transient focal brain ischemia in the rat. Eur J Neurosci 1996;8:2265-2272.

37 Biemond P, Eijk HGN, Swaak AJG, Koster JF: Iron mobilization from ferritin by superoxide derived from stimulated PMN leukocytes. J Clin Invest 1984;73:1576-1579.

38 Berenshtein E, Mayer B, Goldberg C, Kitrossky $\mathrm{N}$, Chevion M: Patterns of metabolization of copper and iron following myocardial ischemia: Possible predictive criteria for tissue injury. J Mol Cell Cardiol 1997;29:3025-3034.

39 Spencer KT, Lindower PD, Buettner GR, Kerber RE: Transition metal chelators reduce directly measured myocardial free radical production during reperfusion. J Cardiovasc Pharmacol 1998;32:343-348.

40 Bolli R, Patel BS, Zhu W: The iron chelator desferrioxamine attenuates postischemic ventricular dysfunction. Am J Physiol 1987;253: H1372-H1380.

41 Williams RE, Zweier JL, Flaherty JT: Treatment with deferoxamine during ischemia improves functional and metabolic recovery and reduces reperfusion-induced oxygen radical generation in rabbit hearts. Circulation 1991; 83:1006-1014.

42 Horwitz LD, Sherman NA, Kong Y, Pike AW, Gobin J, Fennessey PV, Horwitz MA: Lipophilic siderophores of Mycobacterium tuberculosis prevent cardiac reperfusion injury. Proc Natl Acad Sci USA 1998;95:5263-5268.

43 Fantini GA, Yoshioka T: Desferoxamine prevents lipid peroxidation and attenuates reoxygenation injury in postischemic skeletal muscle. Am J Physiol 1993;264:H1953-H1959.

44 Shadid M, Moison R, Steendijk P, Hiltermann L, Berger HM, van Bel F: The effect of antioxidative combination therapy on posthypoxicischemic perfusion, metabolism, and electrical activity of the newborn brain. Pediatr Res 1998;44:119-124.

45 Colletti LM, Remick DG, Campbell DA: Desferal attenuates TNF release following hepatic ischemia/reperfusion. J Surg Res 1994;57:447453. 
46 Van Jaarsveld H, Kuyl JM, Wild NM: Ischemia/reperfusion injury is aggravated by an iron supplemented diet and is partly prevented by simultaneous antioxidant supplementation. Res Commun Mol Pathol Pharmacol 1994;86: 273-285.

47 Arora SA, Gores GJ: The role of metals in ischemia/reperfusion injury of the liver. Semin Liver Dis 1996;16:31-38.

48 Salonen JT, Nyyssönen K, Korpela H, Tuomilehto J, Seppänen R, Salonen R: High stored iron levels are associated with excess risk of myocardial infarction in eastern Finnish men. Circulation 1992;86:803-811.

49 Salonen JT, Nyyssönen K, Salonen R: Body iron stores and risk of coronary heart disease (letter). N Engl J Med 1994;334:1159.

50 Sempos CT, Looker AG, Gillum RF, Makug DM: Body iron stores and the risk of coronary heart disease. N Engl J Med 1994;330:11191124.

51 Baer DM, Takawa IS, Hurley LB: Iron stores are not associated with acute myocardial infarction. Circulation 1994;89:2915-2918.

52 Magnusson M, Sigufsson N, Sigvaldason H, Johannesson M, Magnusson S, Thorgeirsson G: Low iron-binding capacity as a risk factor for myocardial infarction. Circulation 1994;89: 102-108.

53 Ascherio A, Willett WC, Rimm EB, Giovannucci EL, Stampfer MJ: Dietary iron intake and risk of coronary disease among men. Circulation 1994;89:969-974.

54 Morrison HI, Semenciw RM, Mao Y, Wigle DT: Serum iron and fatal myocardial infarction. Epidemiology 1994;5:243-246.

55 Sempos CT, Looker AC, Gillum RF: Iron and heart disease: The epidemiological data. Nutr Rev 1996;54:73-84

56 Sullivan JL: Iron and the genetics of cardiovascular disease. Circulation 1999;100:12601263.

57 Kiechl S, Willeit J, Egger G, Poewe W, Oberhollenzer F: Body iron stores and the risk of carotid atherosclerosis. Circulation 1997;96: 3300-3307.

58 Klipstein-Gobusch K, Koster JF, Grobbee DE, Lindemans J, Boeing H, Hofman A, Witteman JCM: Serum ferritin and risk of myocardial infarction in the elderly: The Rotterdam study. Am J Clin Nutr 1999;69:1231-1236.

59 Tuomainen T-P, Punnonen K, Nyyssönen K, Salonen JT: Association between body iron stores and the risk of acute myocardial infarction in men. Circulation 1998;97:1461-1466.

60 Salonen JT, Tuomainen T-P, Salonen R, Lakka TA, Myyssönen K: Donation of blood as associated with reduced risk of myocardial infarction. Am J Epidemiol 1998;148:445-451.

61 Meyers DG, Stickland D, Molsley PA, Seburg JJ, Wilson JE, Mc Manu BF: Possible association of a reduction in cardiovascular events with blood donation. Heart 1997;78:188-193.
62 Nassar BA, Zayed EM, Title LM, O’Neill BJ, Bata IR, Kirkland SA, Dunn J, Dempsey GI, Toon M-H, Johnstone DE: Relation of HFE gene mutations, high iron stores and early onset coronary artery disease. Can J Cardiol 1998;14: 215-220.

63 Bulaj ZJ, Griffen LM, Jorde LB, Edwards CQ, Kushner JP: Clinical and biochemical abnormalities in people heterozygous for hemochromatosis. N Engl J Med 1996;335:1799-1805.

64 Roest M, van der Schouw YT, de Valk B, Marx JJM, Tempelman MJ, de Groot PG, Sixma JJ, Banga JD: Heterozygosity for a hereditary hemochromatosis gene is associated with cardiovascular mortality in women. Circulation 1999; 100:1268-1273.

65 Tuomainen T-P, Kontula K, Nyyssönen K, Lakka TA, Heliö T, Salonen JT: Increased risk of acute myocardial infarction in carriers of the hemochromatosis gene Cys282Tyr mutation. Circulation 1999;100:1274-1279.

66 Swain J, Gutteridge JM: Prooxidant iron and copper, with ferroxidase and xanthine oxidase activities in human atherosclerotic material. FEBS Lett 1995;368:513-515.

67 Lee T-S, Shiao M-S, Pan C-C, Chau L-Y: Irondeficient diet reduces atherosclerotic lesion in apoE-deficient mice. Circulation 1999;99: 1222-1229.

68 Iribarren C, Sempos CT, Eckfeldt JH, Folson AR: Lack of association between ferritin level and measures of LDL oxidation: The ARIC study. Atherosclerosis 1998;139:189-195.

69 Kiechl S, Aichner F, Gerstenbrand F, Egger G, Mair A, Rungger G, Spögler F, Jarosch E, Oberhollenzer F, Willeit J: Body iron stores and presence of carotid atherosclerosis. Arterioscler Thromb 1994;14:1625-1630.

70 Okada S, Midorikawa O: Induction of rat renal adenocarcinoma by Fe-nitrilotriacetate (FeNTA). Jpn Arch Intern Med 1982;29:385491

71 Okada S, Hamazaki S, Toyokuni S, Midorikawa $\mathrm{O}$ : Induction of mesothelioma by intraperitoneal injections of ferric succhrate in male Wistar rats. Br J Cancer 1989;60:708-711.

72 Toyokuni S, Uchida K, Okamoto K, Hattori Y, Nakakuki Y, Hiai H, Stadtman ER: Formation of 4-hydroxy-2-nonenal-modified proteins in the renal proximal tubules of rats treated with a renal carcinogen ferric nitrilotriacetate. Proc Soc Acad Sci USA 1994;91:2616-2620.

73 Zhang D, Okada S, Yu Y, Pingdong Z, Yamaguchi R, Kasai H: Vitamin E inhibits apoptosis, DNA modification, and cancer induced by iron-mediated peroxidation in Wistar rat kidney. Cancer Res 1997;57:2410-2414.

74 Loft S, Vistisen K, Ewertz M, Tjonneland A, Overvad K, Poulsen HE: Oxidative DNA damage estimated by 8-hydroxy-deoxyguanosine excretion in humans: Influence of smoking, gender and body mass index. Carcinogenesis 1992;13:2241-2247.
75 Mossman BT, Bignon J, Corn M, Seaton A, Gee JBL: Asbestosis: Scientific developments and implications for public policy. Science 1990;247:294-301.

76 Park SH, Aust AE: Participation of iron and nitric oxide in the mutagenicity of asbestos in hpgrt-, gpt+ Chinese hamster V79 cells. Cancer Res 1998;58:1144-1148.

77 Bergeron RJ, Streiff RR, Elliott GT: Influence of iron on in vitro proliferation and lethality of L1210 cells. J Nutr 1985;115:369-374.

78 Thompson HJ, Kennedy K, Witt M, Juzefky J: Effect of dietary iron deficiency or excess on the induction of mammary carcinogenesis by 1-methyl-1-nitrourea. Carcinogenesis 1991;12: 111-114.

79 Diwan BA, Kasprzak KS, Anderson LM: Promotion of dimethylbenz(a)anthracene-initiated mammary carcinogenesis by iron in female Sprague-Dawley rats. Carcinogenesis 1997;18: 1757-1762.

80 Babbs CF: Free radicals and the etiology of colon cancer. Free Radic Biol Med 1990;8: 191-200.

81 Stevens RG, Jones Y, Micozzi MS, Taylor RR: Body iron stores and the risk of cancer. N Engl J Med 1988;319:1047-1052.

82 Yip R, Williamson DF: Body iron stores and the risk of cancer (letter). N Engl J Med 1989; 320:1012.

83 Stevens RG, Graubard BI, Micozzi MS, Neriishi K, Blumberg BS: Moderate elevation of body iron level and increased risk of cancer occurrence and death. Int J Cancer 1994;56: 364-369.

84 Porres JM, Stahl CH, Cheng WH, Fu Y, Roneker KR, Pond WG, Lei XG: Dietary intrinsic phytate protects colon from lipid peroxidation in pigs with a moderately high iron intake. Proc Soc Exp Biol Med 1999;221:80-86.

85 Knekt P, Reunanen A, Takkunen H, Aromaa A, Heliövaara M, Hakulinen T: Body iron stores and risk of cancer. Int J Cancer 1994;56: 379-382.

86 Donfrancesco A, Deb G, DeSio L, Cozza R, Castellano A: Role of deferoxamine in tumor therapy. Acta Haematol 1996;95:66-69.

87 Merk K, Mattsson B, Mattsson A, Holm A, Gullbring G, Björgholm B: The incidence of cancer among blood donors. Int $\mathrm{J}$ Epidemiol 1990;19:505-509.

88 Elsenhans B, Schümann K, Forth W: Toxic metals: Interactions with essential metals; in Rowland IR (ed): Nutrition, Toxicity, and Cancer. Boca Raton, CRC Press, 1991, chap 8, pp 223-258.

89 Pantopoulos K, Hentze MW: Regulation of iron metabolism in higher eukaryotes: Iron-sulfur centers as genetic switches; in Ferreira GC, Moura JJG, France R (eds): Iron Metabolism. Weinheim, Wiley, 1999, pp 131-152. 